\title{
Refleksi nilai-nilai kultural dan linguistik dalam situs haji
}

\section{Cultural value and linguistic reflection in Islamic pilgrim sites}

\author{
Gayda Bachmid \\ Fakultas Ilmu Budaya, Universitas Sam Ratulangi Manado \\ Jalan Kampus Bahu Manado 95115, Sulawesi, Indonesia. Telepon: 0431-863786 \\ E-mail: gaydabachmid14@gmail.com
}

\begin{abstract}
A hidden value reflection in pilgrim ritual texts and pilgrim sites is the creation of the clearest thinking pattern and human behavior through liturgy domain. This is very potential and strategic in the framework of spreading, enlightenment, consolidation and full experience of religious value actualization and faith in life. This research was limited to internal and external linguistic aspects. These two elements were studied and traced through verbal messages (prayer texts). Qualitative method was used through eclectic application, Arabic language theory combination, and semiotics. Research findings indicate there are insya 'thalabi and insya' ghairi thalabi category forms. Insya' thalabi consists of 124 lexical requests in the form of imperative and prohibition. Insya' ghairi thalabi consists of 201 words of admiration, greatness, and adoration to the Creator. Through Badi' science approach, 103 beautiful rhyming forms and 7 repetitive words are found. There are also pledge and promise sentences in the form of declarative, imperative and oath taking in the name of God. The site historical contemplation reflects the values of self-correction, servitude and self-control. The cultural values of the site historical reflection results experienced by the ritual agents are ethics, moral, selfawarwnrss, self-correction, servitude, self-control, spiritual cleansing from disavowal, faith, and spitefulness. Human social valued are democratization, equality, and philosophy.
\end{abstract}

Keywords: value, cultural, linguistic, pilgrim site

\begin{abstract}
Abstrak
Refleksi nilai yang terselubung dalam teks doa ritual haji dan situs haji merupakan penjelmaan dari pola pikir dan perilaku manusia yang paling jelas melalui ranah liturgi. Hal ini sangat potensial dan strategis dalam rangka penularan, pencerahan, pemantapan, dan penghayatan aktualisasi nilai-nilai religius dan keimanan dalam kehidupan. Penelitian ini dibatasi pada aspek internal linguistik dan eksternal linguistik. Kedua unsur ini dikaji dan ditelusuri lewat pesan verbal (teks doa) dengan pendekatan bahasa Arab yakni ilmu Ma'ani dan ilmu Badi'. Penelitian ini menggunakan metode kualitatif dengan penerapan eklektif, kombinasi teori bahasa Arab, dan semiotik. Hasil penelitian ditemukan bentuk kategori insya' thalabi dan insya' ghairi thalabi. Insya' thalabi terdapat 124 leksikal permohonan berbentuk imperatif, dan bentuk larangan. Insya' ghairi thalabi ditemukan kata kekaguman, kebesaran, dan puja pujian pada sang Khalik sebanyak 201 kata. Pendekatan ilmu Badi' ditemukan 103 bentuk persajakan yang indah dan 7 kata ulang. Nilai-nilai bertema ideologis yang ditemukan dari sisi linguistik berupa estetika, kekhusyukan, kepatuhan, perhambaan diri, kesetiaan, kebersamaan, kekaguman akan kebesaran Ilahi. Nilai-nilai kultural dari hasil refleksi sejarah situs yang dilakoni oleh pelaku ritual yaitu etika, moral, kesadaran diri, koreksi diri, perhambaan, pengendalian diri pembersihan batiniah dari berbagai kemungkaran, keyakinan dan kedengkian. Nilai sosial kemanusiaan adalah demokratisasi, persamaan derajat, dan filosofi.
\end{abstract}

Kata kunci: nilai, kultural, linguistik, situs haji

\section{Pendahuluan}

Artikel ini diangkat dari hasil penelitian yang difokuskan pada situs haji dalam pembahasan yang bersifat interdisipliner, yakni saling terintegrasi, dengan penekanan bahwa bahasa adalah rangkaian praktik-praktik kultural yang memainkan peran esensial dalam memediasi ide-ide dan aspek material. Refleksi adalah upaya mendasar untuk menggali dan memperoleh pengetahuan unsur-unsur hakiki untuk dipikirkan secara kritis dalam mendapatkan nilai-nilai yang tersimpan dalam tataran verbal dan nonverbal. Melalui proses reflektif, kita dapat memahami tentang apa yang telah dilakukan manusia haji, memahami fenomena yang realistis di sekitarnya sekaligus realitas yang transenden. Tujuannya untuk menyingkap, mencerahkan dan melestarikan nilai-nilai kultural dan linguistik dalam kehidupan. 
Situs haji dijadikan pilihan yang istimewa, situs haji mencerminkan ideologi dari hakekat makna ritual haji yang seirama dengan doa yang beragam dan dilantunkan pula sesuai situs yang berbeda. Nilai-nilai yang tersimpan dalam situs haji memiliki kekuatan lintas ruang dan waktu yang mampu mengatasi kesenjangan interaksi manusia dan Khalik, manusia dengan sesamanya dan manusia dengan alam raya. Ideologi dalam arti transformasi peristiwa sejarah haji yang menjadi renungan tentang eksistensi individu dan interaksi sosial yang di dalamnya terdapat sejumlah norma berfungsi sebagai penuntun dalam pengendalian diri. Norma petunjuk dalam membangun interaksi sosial yang ramah sesama manusia, makluk binatang dan alam raya.

Situs haji merupakan nomenklatur, objek monumental yang menunjukkan sejarah latar lokalitas tempat berlangsung ritual haji. Hal ini menunjukkan bagaimana budaya yang tetap eksis dan tetap bertahan karena ditransmisikan dari lintas generasi sepanjang hayat. Nilai kultural diidentifikasi sebagai konsekuensi dari tata perbuatan berpola dan perilaku bernorma yang diperan oleh pelaku ritual. Sebagaimana terungkap dalam wawancara bahwa tata ritual di situs haji sangat menyentuh dan membatin di saat bersimpuh bermohon pada Sang Khalik di situs haji, ini mencerminkan nilai-nilai kepatuhan, keikhlasan, dan perhambaan diri pada Sang Khalik.

Nilai linguistik bertolak dari interpretasi daya kognisi terhadap doa ritual yang dirajut dalam bahasa Arab dan merupakan sumber validasi dalam penyingkapan nilai-nilai dalam domain linguistik. Penyingkapan nilai dirasakan tepat dan aktual dari hasil telaah bahasa liturgi (bahasa Arab) sebagaimana secara jujur diakui oleh pelaku ritual dalam wawancara tidak terstruktur

Pembahasan mengenai kedua domain tersebut dibedah lewat pendekatan linguistik- antropologi, yakni mengkaji hubungan bahasa dan budaya, mengaitkan 2 bidang yang dapat dikaji secara terpisah yaitu bahasa oleh linguistik dan budaya oleh antropologi. Karena itu, tulisan ini memanfaatkan teori, hasil kajian atau metodologi dalam antropologi baik secara eksplisit maupun implisit. Temuan teoretis yang penting dalam hal bahasa adalah bagaimana disampaikan Saussure (LittleJohn 1996: 340) yang membedakan antara bahasa formal (language) dan penggunaan bahasa aktual dalam komunikasi (parole)

Bahasa (language) adalah suatu sistem fundamental yang dapat dianalisis terpisah dari penggunaan aktualnya dalam kehidupan sehari-hari. Sementara itu, percakapan (parole) adalah penggunaan bahasa untuk menyampaikan pesan berbagai tujuan.

Kalau kebudayaan diartikan, mengikuti perspektif Fishman (1991: 20-24) melihat 3 macam hubungan di antaranya bahasa dan budaya. Salah satu yang dianggap terkait yaitu bahasa dikatakan berkaitan dengan budaya secara indeksikal karena hanya dengan bahasa yang bersangkutanlah artifak yang dihasilkan budaya itu dapat disingkap dengan tepat.

Demikian pula pengungkapan nilai-nilai budaya dan pandangan dunia hanya dapat dilakukan secara tepat dengan menggunakan bahasa yang bersangkutan. Sehubungan dengan lokalisasi situs berada di jazirah Arab maka bahasa Arab digunakan dalam teks doa. Ini merupakan lambang budaya Arab, yang selanjutnya berimplikasi bahwa sebagian besar pelaku ritual menyatakan ketika diwawancarai bahwa doa yang dilantunkan di situs haji menggunakan bahasa lain, daya magisnya, cita rasanya dan daya tariknya akan hilang. Tidaklah berlebihan jika Bassnett (1992:14) mengibaratkan bahasa dengan jantung ketika dia mengatakan "Languange is the heart within the body of culture."

Keeratan hubungan bahasa dan kebudayaan dipertegas oleh Smoliez (1980:1) yang mengatakan bahwa nilai-nilai inti (Core values) merupakan salah satu komponen yang paling dasar dari kebudayaan suatu masyarakat dan nilai-nilai inti itu mencakup bahasa. Artinya, bahasa adalah penghubung yang tidak terlarutkan (indissoluble link) yang menentukan masyarakat sebagai kelompok sosial budaya yang membedakannya dengan masyarakat lain. 
Masalah yang diangkat dalam penelitian ini adalah bagaimana penyingkapan nilai kultural dan linguistik dalam situs haji. Pertama, bagaimana bentuk-bentuk doa ritual yang mencerminkan nilai linguistik? Kedua, nilai-nilai apa saja yang tersirat dalam situs haji?

Penelitian ini bertujuan untuk a) mendeskripsikan tema-tema ideologis yang terkandung dalam bentuk doa yang menunjukkan suatu muatan nilai-nilai dari sisi misteri baik dalam nilai-nilai kemanusiaan, moral, religi, estetika, dan filosofi yang terkandung dalam bahasa. b) Menyingkap dan mengkaji nilai esensial yang tersirat dalam situs haji.

\section{Metode Penelitian}

Penelitian ini menggunakan metode deskriptif kualitatif dalam penganalisian data berdasarkan fakta yang ada atau fenomena yang secara empiris hidup bagi penggunanya. Data ini dijaring melalui observasi, angket tertutup, responden diminta memberi tanda silang di muka jawaban pilihan. Digunakan pula teknik wawancara mendalam sesuai pengalaman pelaku ritual dari sudut emik. Telaah terhadap persepsi informan bersifat alamiah, sebab peneliti tidak berpeluang untuk melakukan rekayasa terhadap pelaksanaan ritual. Analisis dilakukan secara induktif, menggali data dari pelaku ritual termasuk peneliti dipandang sebagai sumber data atau human instrument.

Data bahasa bersumber pada empat jenis konstruksi doa yang dilantunkan pada empat situs yang dianggap valid dan representatif karena tidak bisa ditinggalkan dalam tata ritual dala m penyingkapan nilai. Pendekatan linguistik antropologi digunakan untuk mengkaji eksistensi manusia haji sebagai pemilik bahasa dan budaya. Konstruksi doa ditelaah dan dianalisis secara aktual sesuai peristiwa sejarah situs, yang tidak lain untuk mendapatkan pemahaman tentang hakekat nilai.

Subjek dan lokasi penelitian ditujukan pada masyarakat yang sudah berhaji dan bermukim di kota Manado. Mereka terhimpun dalam organisasi Ikatan Persaudaraan Haji. Hasil pengolahan data diklarifikasi dengan sejumlah pakar dan narasumber yang kompeten.

\section{Hasil Penelitian dan Pembahasan}

Ilmu yang mengkaji hubungan antara bahasa dan budaya dinamakan linguistik antropologi atau antropologi linguistik (Duranti 1997:9) Malinowski dalam Halliday (1978:4) mengemukakan bahwa melalui antropologi linguistik kita dapat menelusuri bagaimana bentuk-bentuk linguistik dipengaruhi oleh aspek budaya, sosial, mental dan psikologis. Apa hakikat sebenarnya dari bentuk dan makna serta bagaimana hubungan keduanya.

Landasan konseptual merupakan makna yang bersumber dalam alam pemikiran manusia yang diekspresikan dalam rumusan kata-kata. Sekaligus pembuka jalan untuk memikirkan nilai-nilai apa saja yang berhasil diidentifikasi dan apa yang masih membutuhkan penggalian lebih jauh.

Menurut Saussure, kedua hal tersebut tampak dalam tanda atau sebagai unsur kebudayaan. Menurutnya petanda merupakan sebuah nilai yang ditentukan oleh kedudukan tanda dalam hubungan dengan kedudukan tanda lainnya. Gagasan ini sangat berpengaruh pada dunia linguistik. Model semiotika Saussure bersifat mentalistik karena dalam anggapannya referen tidak ada. Dengan demikian, nilai digali atas dasar pertalian tanda-tanda itu sendiri.

Maka alat analisis untuk menyingkap nilai merupakan analisis unit-unit mental. Dunia luar berupa objek (situs) yang konkret dengan sendirinya dapat merefleksikan simbol-simbol yang membentuk citra mental yang menggantikan hal-hal yang terdapat dalam dunia luar.

Nilai adalah sesuatu yang berharga, dihormati, dan dijunjung tinggi sebagai suatu kebenaran, keyakinan yang terpatri dalam kepercayaan untuk dijadikan pedoman. Definisi nilai merupakan suatu deskripsi normatif yang membentuk suatu pandangan terhadap pola-pola perilaku dan tindakan yang konkret terhadap manusia haji. 
Nilai merupakan aspek evaluatif dari sistem keyakinan. Dimensi evaluatif ini mencakup kualitas seperti kegunaan, kebaikan, estetika, kemampuan memenuhi kebutuhan, dan pemberi kepuasan. Nilai kebudayaan biasanya berakar pada falsafah dasar dari suatu kebudayaan sehingga berbeda antara kebudayaan satu dan yang lain. Nilai itu bersifat normatif karena memberitahukan anggota kebudayaan tentang apa yang baik dan buruk, yang benar dan yang salah, apa yang perlu diperjuangkan, dilindungi, ditekuni, dan apa yang dilestarikan.

Fenomena hibridasi bahasa dan budaya yang tercermin dalam situs haji ini sangat menarik. Model analisis Saussure bersifat mentalistik karena dalam anggapannya referensi tidak ada. Dengan demikian kajian tanda perlu dilihat pula dari perspektif semiotika karena fenomena kultural dan linguistik menguak sistem tanda yang saling mengikat dan bersifat konvensional. Di samping itu, membutuhkan interpretasi dan inferensi dalam konteks kultural untuk memperoleh hakekat nilai yang terkandung di dalamnya.

Situs haji (artefak) adalah sejumlah objek monumental sebagai tempat berlangsung ritual haji seperti: Ka'bah, safah Marwah, Arafah, dan Mina. Situs haji merupakan produk sejarah haji dari suatu kurun waktu yang panjang dan merupakan bahan perenungan eksistensial. Di sinilah tanda-tanda nonverbal yang menekan pada fenomena empiris, faktual, dan konkret, tanpa ujaran bahasa sehingga akan terkuak makna di balik pesan.

Pendekatan semiotika tidak pula diabaikan untuk digunakan sebagai interpretasi dalam kajian ini, yaitu trilogi tanda Peirce yaitu ikon, indeks, dan simbol. Ikon merupakan tanda yang menggambarkan ciri utama sesuatu yang menyerupai apa yang direpresentasikannya. Indeks adalah tanda yang hadir secara asosiatif akibat terdapatnya hubungan ciri acuan yang sifatnya tetap (hubungan kausal). Adapun simbol adalah sesuatu yang digunakan untuk menunjuk sesuatu yang lainnya berdasarkan kesepakatan (konvensi).

Pendekatan semiotik secara khusus digunakan untuk mengkaji tanda dalam kehidupan, Ini sejalan dengan (Hoed 2007:3) tanda dalam kehidupan manusia haruslah dimaknakan. Teori bahasa Arab sangat membantu memahami konstruksi teks doa bahasa Arab untuk menyingkap perspektif nilai dalam kajian linguistik. Dua jenis teori bahasa Arab yang dominan digunakan untuk membedah teks doa yaitu: 1) Ilmu Maani untuk mengkaji jenis struktur kalimat yang berimplikasi nilai. 2) Ilmu Badi' yang mengkaji keindahan bahasa melalui struktur persajakan dan makna leksikal yang berimplikasi pada makna ganda, metafora dan lambang-lambang transendental, dan kata-kata pengulangan, katakata beroposisi untuk penguatan dan seruan yang mengandung nilai-nilai kebenaran.

Kajian nilai linguistik bersumber pada sejumlah doa yang dilantunkan di situs Ka'bah, SafahMarwah, Arafah, dan Mina. Bahasa doa bukan sekadar alat komunikasi antara hamba dengan sang Khalik, namun mencakup sekumpulan kata dan kalimat bermakna dalam sebuah prosesi ritual. Ia juga merupakan instrumen kekuatan untuk mengeksploitasi dan menginterpretasi diaspora simbolik yang dipadati oleh berbagai nilai. Dengan demikian makna itu harus disejajarkan dengan konteks sehingga muncul makna afektif sebagai konsekuensi hubungan ekspresi tuturan doa dengan situs tempat dituturkannya. Alunan doa yang mengalun sangat menyentuh dimensi rasa. Hal ini diperkuat dengan pernyataan pelaku ritual bahwa ketika berdoa dihadapan situs mereka merasakan semacam dihipnotis dengan alunan keindahan doa. Doa ritual ada semacam roh yang menyadarkan manusia tentang keagungan, kekuasaan, dan kebesaran Ilahi.

Pendekatan teori bahasa Arab (ilmu Ma'ani dan ilmu Badi') yang diaplikasikan dalam penelitian ini memiliki keunikan tersendiri. Ilmu Ma'ani berkaitan dengan bentuk leksikal dalam konstruksi kalimat. Ungkapan leksikal, sintaksis membutuhkan interpretasi pesan yang tersirat di balik konstruksi doa. Bentuk doa ritual jika dilihat dari satuan struktur bahasa terdiri atas himpunan frasa dan kalimat mencerminkan permohonan, pernyataan, perintah, pemujaan, dan penegasan. Telaah makna leksikal mencakup bentuk kesamaan, kemiripan, kebalikan makna dan ketercakupan makna. Unsur-unsur ini terbentuk dalam kalimat-kalimat penegasan, perintah, pelarangan dan penguatan. 
Ilmu Badi' berkaitan dengan ungkapan-ungkapan bahasa yang memiliki penanda khusus sebagai penghias keindahan tuturan dan keindahan makna dalam suatu teks. Unsur yang menonjol dalam teks doa berupa bentuk-bentuk persajakan yang indah.

\section{Bentuk leksikal pendukung nilai-nilai linguistik}

Pada bagian ini diidentifikasi dan dideskpripsikan aspek leksikal melalui peranti linguistik yang terdapat dalam teks doa. Aspek leksikalisasi tergolong unsur utama dalam konstruksi bahasa Arab. Hal ini sejajar dengan pandangan Chaer (1994) bahwa jumlah leksikal pada suatu bahasa erat kaitannya dengan sistem budaya masyarakat pemilik bahasa. Melalui bahasa manusia tidak hanya mengekspresikan pikirannya, tetapi juga dapat mengkonseptualisasi dan menafsirkan dunia sekitarnya.

Teori bahasa Arab yang diacu dalam ilmu Ma'ani yaitu insya' Thalabi dan insya'ghairi thalabi. Hal ini akan kita lihat pada tumpuan leksikal yang terdapat dalam satuan teks. Ini sejalan dengan Saussure yang membedakan dua macam hubungan yang terdapat dalam satuan bahasa, yaitu hubungan sintagmatik dan hubungan asosiatif (atau paradigmatik). Yang dimaksud dengan hubungan sintagmatik adalah hubungan yang benar-benar ada di dalam suatu kalimat yang bersifat linear. Segmen-segmen berupa kata, frase, dan kalimat berada dalam suatu mata rantai yang sederajat, dan hubungan ini terjadi secara in presentia.

Sedangkan yang dimaksud dengan hubungan asosiatif atau paradigmatik adalah hubungan yang terdapat dalam bahasa tetapi tidak tampak dalam susunan kalimat. Hubungan ini terjadi secara in absentia. Maksudnya salah satu pihak dari satuan bahasa yang berhubungan tidak hadir secara nyata, tetapi keberadaanya dapat diketahui.

\section{Doa melihat Ka'bah}

Doa ini ditemukan sejumlah kata seruan dan larangan. Kata seruan terjadi pengulangan sebanyak empat kali "labbaik" (aku datang memenuhi panggilanmu). Kata larangan la syarika lak (tidak ada sekutu bagimu) sebanyak dua kali. Ini menunjukkan pernyataan tegas dari pendoa sebagai kesaksian energi kepatuhan. Ditemukan perpaduan kata yang beruntun sebagai ekspresi pengakuan seorang hamba yang tidak berdaya bahwa segala isi bumi berupa kenikmatan, kekuasaan adalah milik sang Khalik Penguasa Tunggal. Ditemukan pula ekspresi doa yang memiliki makna asosiatif berisi pujapujian dan kekaguman terhadap Ka'bah sebagai ciri pendekatan insya'ghairi thalabi.

Hal ini sejajar dengan yang dipostulatkan oleh Al-Jarim dan Musthafa (1994: 6) bahwa rangkaian kalimat yang terbentuk dalam ilmu $M a{ }^{\prime} a n i$ memiliki makna yang agung dan jelas sangat berkesan di lubuk hati.

Ditemukan tumpuan leksikal yang tergolong insya thalabi seperti kata perintah (amar) sebanyak dua kali yaitu "zid" (tambahkanlah). Ini menunjukkan bahwa pendoa mengharapkan penambahan kehormatan dan kemuliaan, keagungan, dan kewibawaan dari hubungan asosiatif terhadap Ka'bah. Ekspresi doa ini menunjukan suasana sangat mendesak. Pendoa bermohon apa yang diagungkan pada situs Ka'bah diharapkan dapat dipantulkan pada diri pendoa berupa kemuliaan, kehormatan, keagungan, dan kewibawaan.

Tumpuan leksikal yang sederajat mengandung kebesaran dan kehormatan sebagai ekspresi kekaguman yang tergolong insya'ghairi thalabi yaitu perpaduan kelas kata yang sama dengan makna yang beruntun, seperti kata:

Tasyrifan 'kehormatan' ta'ziman 'kebesaran'

takriman 'kemuliaan' mahabbatan 'kewibawaan' 
Gaya bahasa ini memberi sugesti emosi yang kuat, pelaku merasa suatu kondisi yang khusyuk, rasa aman dan bersih dari penyakit hati. Sebagai isyarat bahwa pelaku sedang bercengkrama dengan Sang Khalik. Hal ini sangat sejalan dengan pernyataan Syariati (2002: 46-47).

Nilai-nilai yang ditemukan yaitu keyakinan yang pasti, kepatuhan, kepasrahan, kehormatan, kemuliaan dan kewibawaan selaku hamba yang tidak berdaya di atas segala kekuasaan Ilahi. Makna doa ini mengacu pada refensi in absentia, secara kontekstual dan faktual mengandung nilai-nilai pengakuan bahwa pelakon sejarah haji yaitu Hajar seorang budak miskin dan berkulit hitam mendapat kehormatan yang luar biasa. Hal ini dibuktikan bahwa kuburannya berdekatan dengan pilar Ka'bah.

\section{Doa sa'i}

Doa ini dilantunkan di bukit Safah-Marwah. Bentuk doa ini terdiri atas insya' ghairi thalabi dan insya' thalabi. Insya' ghairi thalabi sebanyak 98 leksikal berupa puja-pujian terhadap kebesaran Ilahi. Isi doa bersifat pernyataan informatif berkaitan dengan ikrar kebesaran dan keagungan Ilahi. Lantunan doa ini menumbuhkan suatu keyakinan yang pasti bahwa pelaku ritual akan diganjari, diberkati, diampuni dan dikabulkan semua perbuatan kebajikan. Adapun leksikalisasi yang mewakili di antaranya yaitu: Arrahman - Arrahim "Maha Pengasih- Maha penyayang", Alkarim 'Maha mulia', Asysakirun 'Maha pemberi kebaikan'. Insya' talabi ditemukan sebanyak 134 leksikal terdiri atas kata imperatif yang berarti harapan doa yang mendesak: Ighfir 'ampunilah', irham 'sayangilah', wa'fu 'maafkanlah', takarram 'bermurah hatilah', tajawwaz' hapuskanlah dosa kami.

Enam bentuk pernyataan permohonan di antaranya:

"Allahumma hamni bitarkil ma'asi abadan"

'Ya Allah rahmatilah kami sehingga mampu meninggalkan segala kejahatan selama hidup'

Tuturan doa di situs ini dibarengi dengan langkah perbuatan berjalan bolak-balik di bukit SafahMarwah sebanyak 7 kali sebagai representasi sejarah situs Sai yang dilakoni Siti Hajar untuk mencari air di saat putra Ismail menangis kehausan di tengah padang pasir yang tandus dan ganas. Nilai yang ditemukan berupa kekaguman, kesabaran, keyakinan kekaguman, dan keuletan.

\section{Doa wukuf}

Doa ini dipanjatkan di situs Arafah, bentuk doa ini terdiri atas insya' ghairi thalabi dan insya' thalabi. Insya' ghairi thalabi sebanyak 20 leksikal di antaranya: Hayyul 'maha hidup', qayyum 'maha kekal', Arrahman 'maha pengasih', Arrahim 'maha penyayang'. Bentuk Insya' thalabi sebanyak 30 leksikal berupa sejumlah permohonan yang bersifat komprehensif di antaranya: permohonan ampunan bukan hanya untuk diri si pendoa tetapi juga orang tua, sanak keluarga, orang Muslim yang berbuat kebajikan, baik yang hidup maupun yang sudah meninggalkan, orang yang pernah dizalimi, orang yang berpesan untuk didoakan atau pun yang pernah kami berbuat jahat. Permohonan perlindungan dari bencana, permohonan rizki, hindarkanlah kami dari segala kejahatan manusia, jin serta binatang. "Taghfirlana: waliwalidina, auladina, ikhwaninan, ikhwaninaa, aqribainaa, masyayikhina, ashabina, jamiil muslimina walmuslimat, alahyai minhum walamwat”.

Doa wukuf ini dilantunkan di bukit Arafah di saat semua pelaku ritual dalam keadaan berdiam diri dengan memberdayakan potensi daya konsentrasi maksimal dalam menjalin hubungan vertikal dengan sang Khalik. Sejumlah nilai yang terpantul dari doa ini yaitu: nilai kebersamaan, persaudaraan, pengendalian diri, kasih sayang sesama mahkluk manusia, binatang dan alam sekitar.

\section{Doa melontar jumrah}

Doa ini dilantunkan di wilayah Mina di suatu lokasi yang bernama Jamarat. Doa ini diawali dengan bentuk insya' ghairi thalabi berupa puja-pujian akan kebesaran dan maha pengasih Ilahi. Selanjutnya 
teks doa ini didominasi oleh insya' thalabi berupa permohonan agar setan itu dikutuk dan mengharap keridhaan Tuhan agar ritual haji pendoa diterima.

Sejumlah permohonan berupa belas kasihan terhadap diri pelaku ritual, melipatgandakan pahalaku, penerima tobatku, perkecil kekeliruannku, perkenankan lah permintaanku. Contoh: Waa'zhim ajri 'perbesarlah pahalaku', warham tadharrui 'kasihanilah kerendahan hatiku', waqbal taubatii, 'terimalah tobatku', waaqilla taubatii, 'perkecilah kekeliruanku'.

Nilai-nilai yang ditemukan berdasarkan makna asosiatif sehubungan dengan kutukan Allah terhadap setan yang tetap menggoda keturunan Adam sampai pada nabi Ibrahim di saat memenuhi panggilan Tuhan untuk menyembelih putra Ismail. Nilai yang dicerminkan dari doa ini merupakan pembalikan makna dari sifat dan sikap syetan yang ingkar yang berjanji kepada Tuhan untuk tetap menggoda manusia. Sikap pendoa dalam posisi berlawanan dengan syetan yaitu memperhamba diri, kepatuhan, dan merendahkan hati.

\section{Nilai estetika}

Dengan gaya bahasa bersifat padat dan mampat ditemukan leksikal dan frasa dalam posisi sederajat. Contoh:

Hajjan mabruran 'haji yang diterima Allah

Sya'yan masykuran sa'i yang diterima

Kata tersebut mendapat penekanan di bagian akhir kalimat dengan rima aa sebagai unsur penekanan huruf mati di akhir kata yang menurut pelaku ritual sangat syahdu dan menyejukan.

\section{Situs haji pendukung nilai-nilai kultural}

\section{Ka'bah}

Ka'bah berdasarkan literatur Arab disebut Ka'bah bangunan yang berbentuk kubus yang disebut Baitullah (Rumah Tuhan) atau Baitul Stiq (Rumah Kemerdekaan). Ka'bah berkedudukan di tanah Haram. Wilayah hening dan damai. Wilayah terlarang dari perkelahian dan pertumpahan darah, terjaga dari pengrusakan tumbuhan dan pencemaran alam.

Secara visual Ka'bah merupakan bangunan yang secara fisik tidak memiliki ornamen dan gaya arsitektur yang fantastik. Berdiri tegak sejak ribuan tahun yang silam, tidak pernah sepi dan membosankan dikunjungi oleh jutaan manusia sepanjang tahun. Hal ini dibuktikan ketika pelaku ritual melantunkan doa diakhir prosesi ritual haji mereka bermohon bahwa kedatangan mereka kali ini di rumah Tuhan bukan untuk yang terakhir kali.

\section{Nilai egalitas}

Di situs ini terdapat kuburan Siti Hajar kuburannya berdekatan dengan pilar Ka'bah, seorang budak miskin dan berkulit hitam yang mendapat kehormatan luar biasa. Ini suatu keajaiban sekalipun para nabi, tidak dikuburkan di tempat itu. Situs ini adalah tempat dilangsungkan ritus tawaf, jutaan pelaku ritual tampil mengitari Ka'bah dalam status dan derajat yang sama di mata Tuhan. Simbolisasi kehormatan, keagungan dan kewibawaan sebagai suatu ikon yang dilakoni Hajar.

\section{Nilai etika}

Dalam pelaksanaan ritus pelaku ritual dalam keadaan bersih diri dan mawas diri dengan konsistensi niat, keteguhan iman untuk menjaga Rumah Allah. Ini memberi arti bahwa etika dalam hal ini perlu dijaga jangan sampai terjadi deformasi niat yang menyimpang dari niat ibadah. 


\section{Nilai filosofi}

Secara kasat mata bangunan Ka'bah tidak menarik hanya bangunan batu serba hitam. Namun pada umumnya para pelaku ritual jiwanya terpantul daya spiritual yang amat dalam, muncul rasa ketakjuban sampai bertetesan air mata. Bahkan Ka'bah dirindukan oleh berjuta manusia sepanjang hayat. Di dalamnya terkandung nilai kehormatan, kebesaran dan keaguangan.

\section{Safa-marwah}

Situs ini merupakan tapak tilas pengalaman dan penderitaan Sitti Hajar di saat mencari air untuk anaknya berjalan bolak balik sebanyak 7 kali sepanjang 2.835 meter.

Nilai kesabaran, ketangguhan dan ketaqwaan Siti Hajar wanita sejati yang sangat memahami perintah Tuhan. Ia meninggalkan rumahnya bersama bayinya yang masih menyusui menuju lembah padang pasir gersang yang tidak berpenghuni dan menakutkan.

\section{Nilai religi}

Nilai mencerminkan sikap dan persepsi bahwa tempat ini sa'i dianggap sakral dan megah. Kesakralan sebagai penghormatan tempat pemukiman wanita agung yang membesarkan Ismail di atas pangkuannya. Sedangkan kemegahan situs ini disimbolkan dalam wujud monumen yang tetap dirawat dengan indah untuk diabadikan sepanjang masa.

\section{Nilai moral}

Sikap kepasrahan Hajar yang tulus menerima perintah Allah dijadikan model sebagai manusia yang memiliki tanggung jawab moral dalam kehidupan keluarga. Ia ditinggalkan suaminya Ibrahim, seorang diri di padang yang tandus tapi tidak mengeluh dan berpangku tangan. Ia memutuskan untuk menggantungkan hidupnya secara mandiri, mengerahkan pikiran dan tenaga untuk terus bergerak menghidupkan putranya.

\section{Nilai filosofi}

Situs ini menstimulasi daya pikir dan kesadaran pelaku ritual untuk bermeditasi berupa perenungan mencari kebenaran hakiki tentang fenomena sejarah yang dialami Siti Hajar. Ia bergumul secara realistis untuk berjuang dengan gigih mengatasi kesulitan melampaui realitas demi kehidupan anaknya Ismail. Inilah perilaku budaya yang dilakoni Hajar yang dijadikan pembelajaran bagi pelaku ritual untuk mengisi hidupnya dengan penuh makna.

\section{Arafah}

Padang pasir yang terletak $25 \mathrm{~km}$ sebelah timur kota Mekah. Hamparan pasir dan batu yang luas tidak berpenghuni di kelilingi bukit-bukit batu yang berbentuk setengah lingkaran. Di sinilah seluruh Ummat Islam di dunia datang serentak dalam waktu yang sama untuk melakukan wukuf. Di tempat ini terdapat sebuah bukit bernama Jabal Rahmah (bukit kasih sayang), tempat perjumpaan Nabi Adam dan Hawa setelah dipisahkan Allah di muka bumi selama 200 tahun.

Pelaku ritual berdiam diri dengan kostum yang sama berwarna putih. Semua perbedaan yang maha dahsyat dilebur di tempat ini. Aristokrasi menjadi tidak bernilai dan kebanggaan rupa dan fisik tidak menimbulkan daya tarik. Ikonisasi, indekskalisasi dan simbolisasi menyatu dalam situs ini yang tergambar dalam sejumlah nilai yaitu: 


\section{Nilai egalitas dan demokratisasi}

Seluruh pelaku ritual berada dalam suatu meditasi dengan pakaian ihram yang tidak ada beda antara satu dengan yang lain. Ini simbolisasi dengan persamaan derajat antara rakyat biasa dengan orang bangsawan, orang berpangkat dengan orang kebanyakan kesemuanya sama di mata Tuhan

\section{Nilai etika}

Pelaku ritual wajib tunduk pada sejumlah larangan ketika wukuf di Arafah. Selama kostum ihram masih melekat di tubuh wajib membentuk sikap ramah baik sesama manusia haji, tumbuh-tumbuhan, hewan ternak. Tidak ada perlakuan menyakitkan, membinasakan semua ciptaan Tuhan.

\section{Nilai moral}

Pelaku ritual dalam posisi menyatu dalam persaudaraan dengan berbagai ras, suku bangsa. Menghindari tuturan dan sikap yang membawa pertentangan.

\section{Nilai filosofi}

Refleksi suasana Arafah menyiratkan suatu pengetahaun baru bagi ummat manusia berupa petunjuk tentang kesadaran dan pembebasan dari dosa. Simbol pancaran kasih sayang manusia pertama yang saling merindukan setelah terpisah ribuan tahun.

\section{Mina}

Situs ini berupa sebuah hamparan padang pasir yang panjangnya sekitar $3.5 \mathrm{~km}$, terletak di kawasan berbukit-bukit antara kota Mekah dan Muzdalifah. Dewasa ini telah berkembang sehingga perluasan kota Mekah dan Mina hampir bersambung. Mina bagian dari Tanah Haram Mekah. Tempat ini dikunjungi pelaku ritual selama 3-4 hari sebelum wukuf di Arafah. Di situs ini diberlakukan amalan wajib haji yaitu melontar.

Di lembah gersang ini tidak ada yang indah untuk ditonton, tidak aman untuk wisata. Di sinilah konvensi Mina yang diselenggarakan di udara terbuka di bawah langit tanpa dinding. Pelaku hanya duduk termenung di bawah pengawasan Sang Khalik sebagai penjaga. Lemparan (jumrah) merupakan simbolisasi kekuatan setan yang senantiasa mengincar manusia dan menyergap manusia ketika manusia tidak mengikuti tapak tilas nabi Ibrahim.

Lemparan (jumrah) merupakan simbol untuk membasmi setan, serta membasmi penindasan, penyesatan, dan penciptaan deskriminasi pemecah belah persatuan. Gerakan ini merupakan simbol kemenangan manusia atas godaan setan dalam melaksanakan semblihan ibadah kurban.

\section{Nilai etika}

Ritus ini dilakukan dengan suatu aksi yang beraturan. Pelaku ritual memulai niat dan doa. Tindakan yang tidak disertai niat tidak diterima. Permohonan ikrar sebagai benteng perlindungan dalam diri untuk mengalahkan iblis.

\section{Nilai moral}

Situs ini simbolisasi napak tilas nabi Ibrahim. Lemparan ini ada isyarat, ada suatu perlakuan dengan lemparan batu kerikil karena setan tidak menampakan dengan kasat mata. Kemenangan nabi Ibrahim merupakan simbolisasi kekebalan, kekuatan, dan kesakralan yang tidak terkalahkan untuk menghadapi musuh manusia. 


\section{Nilai filosofi}

Nabi Ibrahim sebagai manusia biasa memiliki potensi yang dialektis dengan keraguan dalam menentukan pilihan antara keyakinan dan keingkaran. Di sinilah cinta sejati Ibrahim yang sangat kuat yang ada dalam diri Ibrahim, ia menghancurkan perasaan suka mementingkan diri sendiri menjadi senjata yang ampuh untuk memerangi setan.

\section{Simpulan}

Simpulan ditarik berdasarkan hasil pembahasan dari empat jenis doa dan empat situs haji dengan pendekatan linguistik antropologi dan divalidasi dengan pemahaman perspektif emik dari pelaku ritual. Penyingkapan nilai-nilai linguistik dibedah melalui pendekatan bahasa Arab yaitu ilmu Ma'ani dan ilmu Badi'. Bentuk doa menurut pendekatan Ma'ani digolongkan dalam dua kategori yaitu Insya thalabi (permohonan dan harapan) dan Insya'ghairi thalabi (puja-pujian kepada sang Khalik). Penyingkapan nilai-nilai budaya disejajarkan dengan konteks pemahaman sejarah situs haji yang menjadi lokalisasi doa dilantunkan dan dibedah pula dengan pendekatan semiotika. Bentuk doa ditandai dengan sejumlah penanda dalam struktur leksikalisasi, berupa bentuk kata perintah, kata seruan, kata larangan, pengakuan, persajakan, dan puja-pujian.

Nilai linguistik yang dikandung dalam empat jenis doa adalah sebagai berikut 1) nilai kepatuhan, 2) nilai kepasrahan, 3) nilai kekuatan, 4) nilai kemuliaan, 5) nilai kewibawaan, 6) nilai kesetiaan, 7) nilai kesabaran, 8) nilai keyakinan, 9) nilai kekaguman, 10) nilai keuletan, 11) nilai kebersamaan, 12) nilai persaudaraan, 13) nilai pengendalian diri, 14) nilai kasih saying, 15) nilai estetika, 20) nilai perhambaan diri, dan 21) nilai merendahkan diri.

Nilai Budaya yang dikandung dalam empat situs yaitu Ka'bah, Safah-Marwah, Arafah dan Mina yaitu: 1) nilai egalitas, 2) nilai etika, 3) filosofi, 4) nilai religi, 5) kesabaran, 6) ketangguhan, 7) ketaqwaan, dan 8) demokratisasi.

\section{Daftar Pustaka}

Al-Hasyimi A (1960) Jawahir Al Balaghah. Jakarta: Raja Grafindo Persada.

Aljarimi A dan Musthafa U (1987) Terjemahan Al Balaghatul Waadhihah. Bandung: Sinar Baru Algensindo.

Basnett S (1992) Translation studies. London/New York: Metheun.

Chaer A (1994) Linguistik umum. Jakarta: Rineke Cipta.

De Saussure F (1988) Pengantar linguistik umum, diterjemahkan oleh Rahayu S. Hidayat, Seri ILDEP. Yogyakarta: Gajah Mana University Press.

Duranti A (1997) Linguistic antropology. Cambridge: Cambridge University Press.

Fishman JA (1991) Reversing language shift: Theoretical and Emperical Foundation of Assistance Threatened Language. Clevedon UK: Multilingual matters.

Halliday (1978) Language and social semiotic: The Social Interaction of language and meaning. Baltimore, MA: University park press.

Hoed BH (2008) Semiotik dan dinamika sosial budaya. Jakarta: Fakultas Ilmu Budaya Universitas Indonesia.

LiitleJohn SW (1996) Theories of human communication, fith edition. New York: Wadsworth publishing company.

Smoliesz J (1980) Language as a core values of culture. Relc Journal Voll 11 N0 1:1-13.

Syariati A (2002) Makna haji. Jakarta: Pustaka Ahra.

Zaimar O (2008) Semiotik dan penerapannya dalam karya sastra Jakarta: Pusat bahasa.

Zaman BM (2009) Senandung doa Ibadah Haji. Jakarta: PT. Golden Terayon Press. 